\title{
Challenges in the control of COVID-19 outbreaks caused by the delta variant during periods of low humidity: an observational study in Sydney, Australia
}

\author{
Michael P. Ward ${ }^{1 *}$, Yuanhua Liu², Shuang Xiao ${ }^{3}$ and Zhijie Zhang ${ }^{2^{*}}$
}

\begin{abstract}
Background: Since the appearance of severe acute respiratory coronavirus 2 (SARS-CoV-2) and the coronavirus disease 2019 (COVID-19) pandemic, a growing body of evidence has suggested that weather factors, particularly temperature and humidity, influence transmission. This relationship might differ for the recently emerged B.1.617.2 (delta) variant of SARS-CoV-2. Here we use data from an outbreak in Sydney, Australia that commenced in winter and time-series analysis to investigate the association between reported cases and temperature and relative humidity.

Methods: Between 16 June and 10 September 2021, the peak of the outbreak, there were 31,662 locally-acquired cases reported in five local health districts of Sydney, Australia. The associations between daily 9:00 am and 3:00 pm temperature $\left({ }^{\circ} \mathrm{C}\right)$, relative humidity $(\%)$ and their difference, and a time series of reported daily cases were assessed using univariable and multivariable generalized additive models and a 14-day exponential moving average. Akaike information criterion (AIC) and the likelihood ratio statistic were used to compare different models and determine the best fitting model. A sensitivity analysis was performed by modifying the exponential moving average.

Results: During the 87-day time-series, relative humidity ranged widely $(<30-98 \%)$ and temperatures were mild (approximately $11-17^{\circ} \mathrm{C}$ ). The best-fitting (AIC: 1,119.64) generalized additive model included 14-day exponential moving averages of 9:00 am temperature $(P<0.001)$ and 9:00 am relative humidity $(P<0.001)$, and the interaction between these two weather variables $(P<0.001)$. Humidity was negatively associated with cases no matter whether temperature was high or low. The effect of lower relative humidity on increased cases was more pronounced below relative humidity of about 70\%; below this threshold, not only were the effects of humidity pronounced but also the relationship between temperature and cases of the delta variant becomes apparent.

Conclusions: We suggest that the control of COVID-19 outbreaks, specifically those due to the delta variant, is particularly challenging during periods of the year with lower relative humidity and warmer temperatures. In addition to vaccination, stronger implementation of other interventions such as mask-wearing and social distancing might need to be considered during these higher risk periods.
\end{abstract}

Keywords: Meteorological factor, Climate, Humidity, Temperature, SARS-CoV-2, COVID-19, Australia

\footnotetext{
*Correspondence: michael.ward@sydney.edu.au; zhj_zhang@fudan.edu.cn

'Sydney School of Veterinary Science, The University of Sydney, Camden,

NSW, Australia

${ }^{2}$ School of Public Health, Fudan University, Shanghai, China

Full list of author information is available at the end of the article
} permits use, sharing, adaptation, distribution and reproduction in any medium or format, as long as you give appropriate credit to the original author(s) and the source, provide a link to the Creative Commons licence, and indicate if changes were made. The images or other third party material in this article are included in the article's Creative Commons licence, unless indicated otherwise in a credit line to the material. If material is not included in the article's Creative Commons licence and your intended use is not permitted by statutory regulation or exceeds the permitted use, you will need to obtain permission directly from the copyright holder. To view a copy of this licence, visit http://creativecommons.org/licenses/by/4.0/. The Creative Commons Public Domain Dedication waiver (http://creativeco mmons.org/publicdomain/zero/1.0/) applies to the data made available in this article, unless otherwise stated in a credit line to the data. 

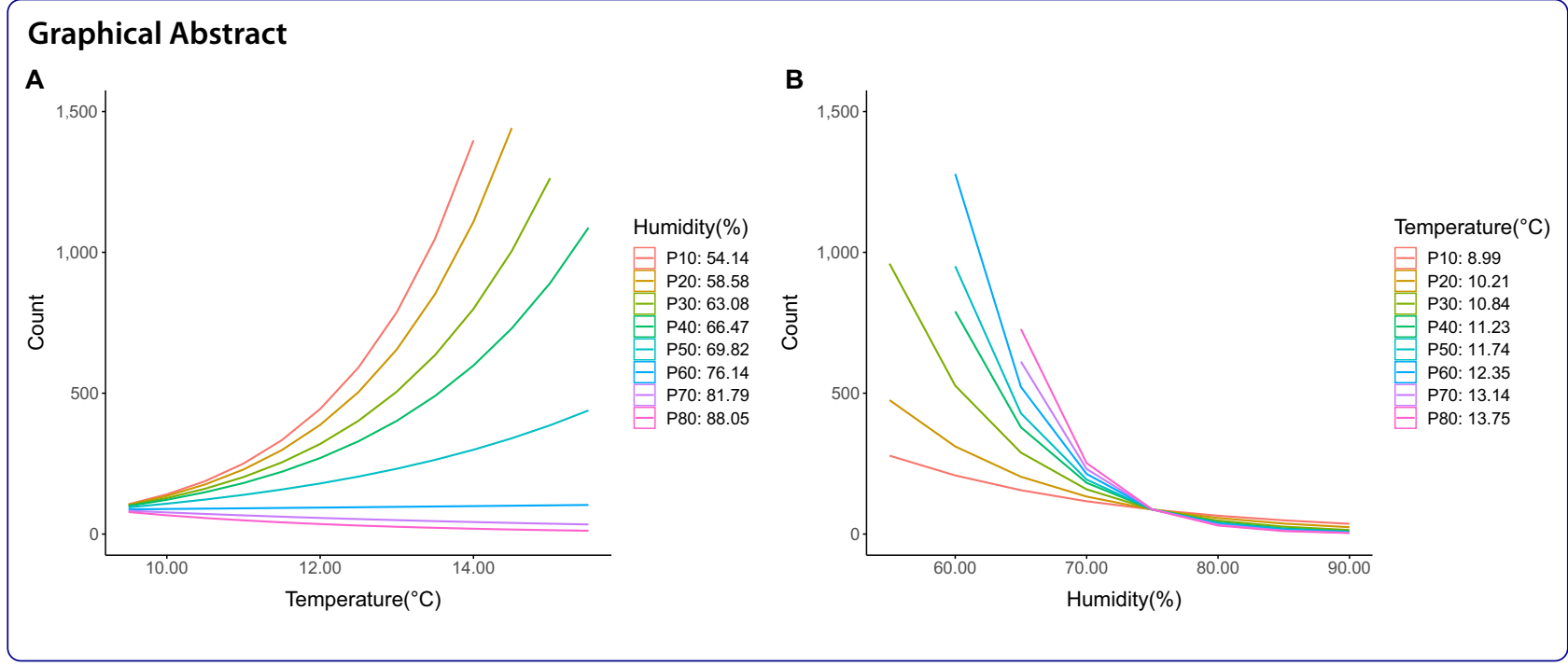

\section{Background}

Severe acute respiratory coronavirus 2 (SARS-CoV-2), the cause of the coronavirus disease 2019 (COVID-19) pandemic, spreads among people predominantly via respiratory droplets and aerosols, as well as fomites [1] and possibly fecal-oral [2]. Although the effect of weather on the airborne spread of SARS-CoV-2 has been investigated in some detail [3], the conclusions are inconsistent. Qi et al. [4] found that temperature had significantly negative associations with COVID-19 incidence in China using province-based data, but Guo et al. [5] showed that warmer weather might not affect COVID-19 spread based on city-scale data from China. In contrast, evidence from Jakarta, Indonesia showed that increased temperature was an environmental driver of COVID-19 outbreaks [6]; a similar conclusion was made in a global study of 190 countries conducted on data from early in the pandemic [7]. Similar contradictory results exist for humidity [6, 8-11]. One explanation is that interactions exist between temperature and humidity and their effect on SARS-CoV-2 transmission, so that the roles of these factors might be heterogenous depending on different climatic zones [12]. But whether and how the interaction among weather factors affects the spread of SARS-CoV-2 remains unclear.

Of more concern, the B.1.617.2 (delta) variant of SARS-CoV-2, first detected in India in December 2020, has spread throughout most of the world during 2021 to become the dominant strain of SARS-CoV-2 [13]. On 16 June, 2021 New South Wales Health was notified of a new COVID-19 case who was residing in Sydney's eastern suburbs. The case, a man in his 60s, had no recent overseas travel history. However it was noted that he worked as a driver, which included transporting international flight crew [14]. Subsequently, an outbreak of COVID-19 caused by local-transmission of the delta variant commenced during early winter (June) in Sydney. To our knowledge, no studies have reported the relationship between weather and transmission of this new variant of SARS-COV-2 specifically in the southern hemisphere winter. Thus, the aim of the present study was to describe the association between reported cases of COVID-19 due to the delta variant and temperature and relative humidity.

Whilst this study builds on previous research conducted in Sydney in 2020, it also extends our knowledge about how temperature and humidity interact in terms of COVID-19 outbreaks, facilitating rational explanations for previously inconsistent study results and the behavior of a new SARS-CoV-2 variant in a predominantly susceptible population during winter, a risk period during which transmission is likely facilitated.

\section{Methods \\ Case data}

Case reports from the local health districts (LHDs) of Sydney, Australia from the beginning of the SARS-CoV-2 delta variant outbreak on 16 June to 30 September 2021 were accessed [15]. COVID-19 surveillance is based on testing (PCR on nasal and oral swabs) contacts of confirmed cases and also testing symptomatic patients. Prior to the index case, the most recent locally-acquired case had been identified on 5 May 2021. During the study period, whole genome sequencing was used to identify variants of concern on a proportion of samples from confirmed cases, and only the delta variant was found. More broadly between 29 November 2020 and 2 October 2021, 
a total of 11,166 cases (about $21 \%$ of all cases) were subject to whole genome sequencing and of these 11,173 (>99.9\%) were identified as the delta variant; only 6 cases of the alpha variant and one case of the beta were identified [16]. Although it is unlikely that all cases that occurred during the study period were ascertained in the surveillance system, this likely represents minor non-differential bias.

Those cases whose infection source was reported to be locally-acquired, and whose LHD of residence was reported as Northern Sydney, South Eastern Sydney, South Western Sydney, Sydney or Western Sydney LHD, were included. A daily time-series of cases was created as the sum of cases reported each day. Daily reports were plotted and using a 7-day moving-average, the peak of the outbreak (1181 cases) was identified on 10 September, 2021 (Fig. 1). Therefore, further analysis was focused on the period from the beginning of the outbreak to its peak, a period of 87 days.

\section{Descriptive analysis}

Based on the reported LHD, cases were linked to weather observation stations [17]. Daily observations of temperature $\left({ }^{\circ} \mathrm{C}\right)$ and relative humidity (\%) recorded at 9:00 am and at 3:00 pm during June to September were accessed [17]. Additional series of daily differences between 9:00 am and 3:00 pm temperature and 9:00 am and 3:00 pm relative humidity were created to indicate the variations. In addition, daily reported number of COVID-19 tests and number of COVID-19 vaccinations administered [18], and the mobility index for Sydney [19], were accessed and time-series created. These variables were included for descriptive purposes only, to provide context regarding this outbreak of COVID-19 caused by the SARS-CoV-2 delta variant.

\section{Statistical modelling}

The same method used in previous studies was applied to investigate the relationship between reported cases of COVID-19 and weather variables [4, 8, 9, 12, 20]. A Spearman correlation $(\rho)$ coefficient matrix was first calculated to avoid multicollinearity among the predictor variables, and a 14-day exponential moving average (EMA) was used to represent the effects of weather factors. Then, a univariable generalized additive model (GAM) was fitted and variables with a $P$-value $<0.1$ were selected for multivariable analysis. Different multivariable analysis models were then fit to analyze the relationship between the selected weather variables and cases of COVID-19. Akaike information criterion (AIC) and likelihood ratio test were used to compare different models and determine the best model. R4.0.1 software [21] was used to perform all analyses.

A sensitivity analysis was performed by modifying the EMA (14 days to 7 or 21 days) to verify the robustness of model results.

\section{Results \\ Epidemic characteristics}

Between 16 June and 10 September 2021, 31,662 locallyacquired cases with a residence within the five target LHDs were notified, excluding 6 and 191 cases in which infection was acquired interstate and overseas, respectively. During this period, relative humidity was variable,

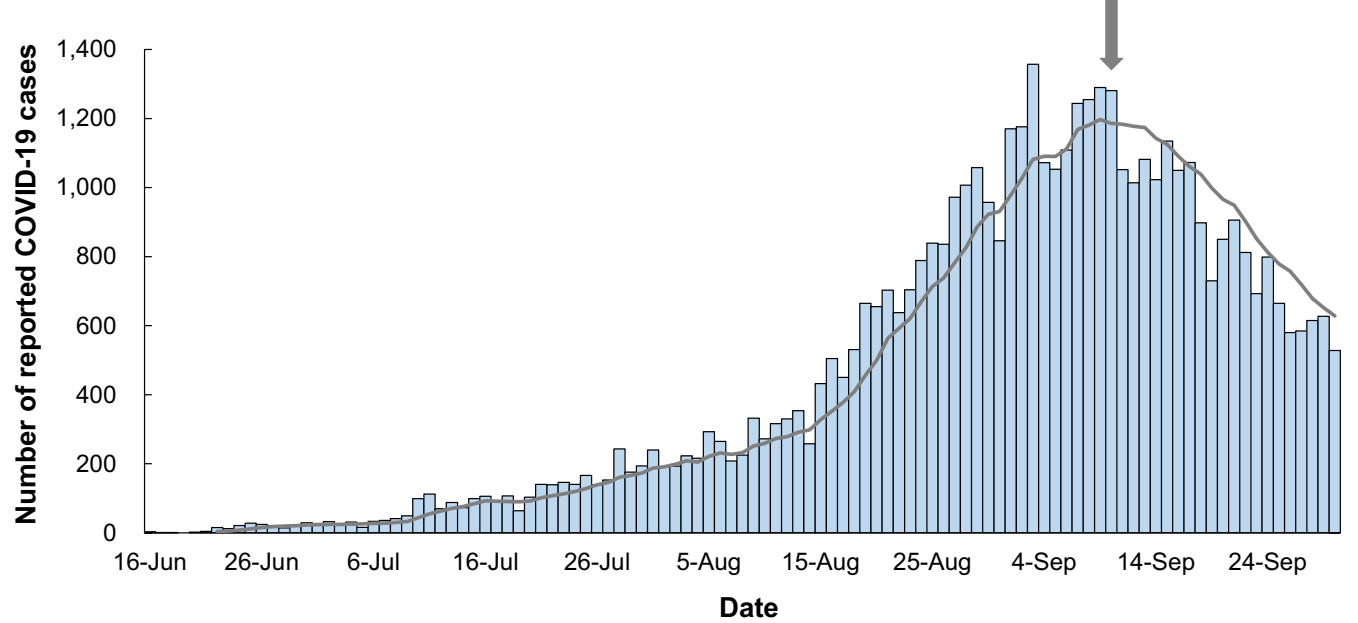

Fig. 1 Time-series plot of cases of COVID-19 due to SARS-CoV-2 delta variant reported from Sydney, Australia during the period of 16 June and 30 September, 2021. The grey line indicates the 7-day moving average of reported cases, and the peak of the outbreak (10 September) is indicated by the arrow 
ranging from $<30 \%$ to $98 \%$, and temperatures were mild (approximately $11-17{ }^{\circ} \mathrm{C}$ ) (Table 1 ). The relationship between 9:00 am temperature and reported cases, and 9:00 am relative humidity and reported cases, as examples are shown in Fig. 2. In this outbreak during the period 16 June to 10 September there was a strong positive correlation between reported cases and the daily number of vaccine doses administered [Spearman rank correlation $(\rho)=0.81, P<0.001]$ and daily number of COVID-19 tests performed $(\rho=0.95, P<0.001)$. These metrics increased from approximately 30,000 to 120,000 doses per day, and 17,000 to 148,000 tests per day, during the period. The relationship between reported cases and the mobility index for Sydney was strongly negative $(\rho=-0.86, P<0.001)$; the mobility index dropped from 0.46 to 0.09 during the study period. Thus, there was a strong response to the occurrence of this outbreak.

\section{Relationship between COVID-19 and weather}

Based on correlation coefficients (Table 2), 9:00 am temperature, 9:00 am humidity and the difference between 9:00 am and 3:00 pm humidity were selected for further analysis; the latter did not show significance in univariable modelling ( $P=0.621$; Table 3$)$. In multivariable modelling, four models with 9:00 am humidity, 9:00 am temperature or an interaction between these variables were fit to the data (Table 4). The model which included the interaction term showed the best fit (Table 5). Lower humidity was a consistent driver of COVID-19 cases caused by the SARS-CoV-2 delta variant, with a slight modification due to a significant interaction term (from -0.110 to -0.185 , setting 9:00 am temperature at its median value). In contrast, the impact of higher temperatures on increased COVID-19 cases was mostly affected by the interaction term [from 0.25 (significant) to 0.04 (almost non-significant), setting 9:00 am humidity at its median value]. These exposure-response curves indicate that when humidity is high there is no effect of temperature on cases (Fig. 3A). However, when humidity is low, high 9:00 am temperatures are associated with more cases. But it should be noted that the range of 9:00 am temperature values during the study period (2.5th97.5th percentile range: $7.3-18.1{ }^{\circ} \mathrm{C}$ ) was relatively narrow and temperatures were mild, favorable conditions for COVID-19 transmission. Relative humidity remained negatively associated with cases no matter whether the 9:00 am temperature was high or low. The effect of lower relative humidity on increased cases was more pronounced below relative humidity values of about $70 \%$ (Fig. 3B); below this threshold, not only are the effects of humidity pronounced but also the relationship between temperature and cases of the delta variant becomes apparent (Fig. 3A).

The sensitivity analysis confirmed that the results of modelling were robust (Table 6).

\section{Discussion}

During the outbreak of COVID-19 in Sydney, beginning June 2021 and caused by the B.1.617.2 (delta) variant of SARS-CoV-2, low humidity was consistently associated with reported cases. Furthermore, and with implications for the response to outbreaks caused by the delta variant, we identified a threshold effect of low relative humidity $(<70 \%)$ whereby warmer, drier conditions might promote transmission of the SARS-CoV-2 delta variant. In addition to vaccination, stronger implementation of other interventions-such as mask-wearing and social distancing-might need to be considered during these risk periods to control outbreaks of COVID-19 caused by the delta variant.

Previously, in 2020, we identified a relationship between the original SARS-CoV-2 and relative humidity [8, 9]. In these earlier studies, a $1 \%$ decrease in relative humidity was predicted to increase cases in the range of $6-8 \%$. In contrast, in the current study in the univariable model which included 9:00 am humidity, a 1\% decrease in relative humidity was predicted to increase cases by $16.9 \%$ (setting 9:00 am temperature at its median value). Although outbreaks in Sydney in 2020 and 2021 cannot be directly compared, results suggest that the influence

Table 1 Summary statistics of weather variables, Sydney, Australia from 16 June to 10 September, 2021, used in a study of an outbreak of COVID-19 caused by the B.1.617.2 (delta) variant of SARS-CoV-2

\begin{tabular}{llccccc}
\hline Variables & Minimum & 2.5th percentile & Median & Mean & 97.5th percentile & Maximum \\
\hline 9:00 am humidity, \% & 32.7 & 49.6 & 69.8 & 72.1 & 96.6 & 98.2 \\
3:00 pm humidity, \% & 21.3 & 27.8 & 47.2 & 50.9 & 91.7 & 98.4 \\
9:00 am temperature, ${ }^{\circ} \mathrm{C}$ & 7.1 & 7.3 & 11.8 & 12.1 & 18.1 & 21.0 \\
3:00 pm temperature, ${ }^{\circ} \mathrm{C}$ & 9.1 & 11.6 & 17.1 & 17.2 & 23.0 & 26.3 \\
Humidity difference, $\%$ & 0.3 & 3.0 & 24.8 & 23.1 & 43.1 & 53.6 \\
Temperature difference, ${ }^{\circ} \mathrm{C}$ & 0.1 & 0.5 & 5.0 & 5.2 & 9.2 & 11.4 \\
\hline
\end{tabular}



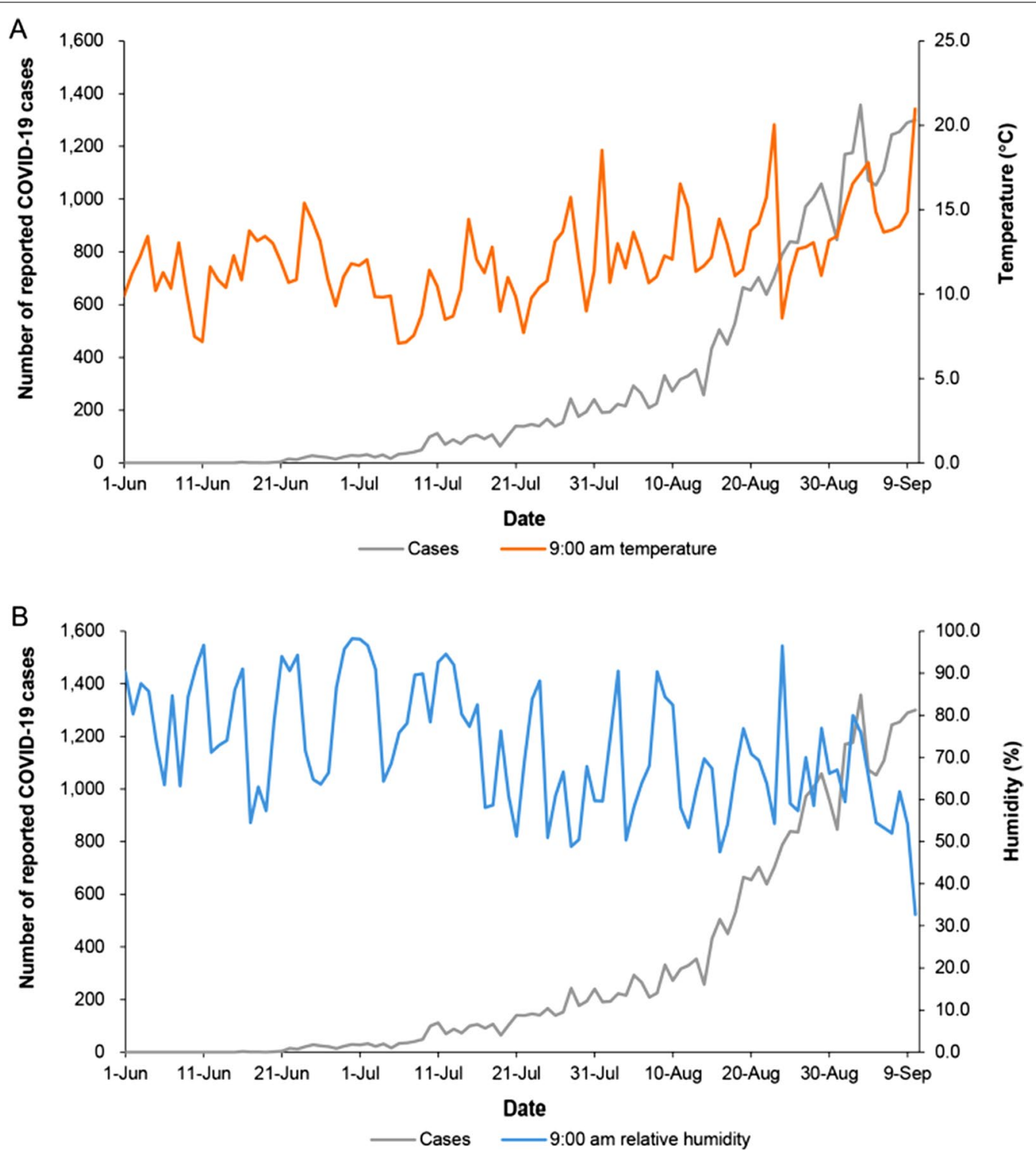

Fig. 2 Reported cases of COVID-19 caused by the B.1.617.2 (delta) variant of SARS-CoV-2, Sydney, Australia 16 June to 10 September 2021 (primary axis) and 9:00 am temperature $\left({ }^{\circ} \mathrm{C}\right)$ and 9:00 am relative humidity (\%) (secondary axes)

Table 2 Spearman correlation coefficient matrix among weather variables used to model reported cases of COVID-19 caused by the B.1.617.2 (delta) variant of SARS-CoV-2, Sydney, Australia from 16 June to 10 September, 2021

\begin{tabular}{lllllll}
\hline Variables & $\begin{array}{l}\mathbf{9 : 0 0} \text { am } \\
\text { temperature }\end{array}$ & $\mathbf{9 : 0 0}$ am humidity & $\begin{array}{l}\mathbf{3 : 0 0} \mathbf{~ p m} \\
\text { temperature }\end{array}$ & $\mathbf{3 : 0 0 ~ p m ~ h u m i d i t y}$ & $\begin{array}{l}\text { Temperature } \\
\text { difference }\end{array}$ & $\begin{array}{l}\text { Humidity } \\
\text { difference }\end{array}$ \\
\hline 9:00 am temperature & 1 & $-0.53^{*}$ & $0.64^{*}$ & $-0.33^{*}$ & -0.15 & -0.10 \\
9:00 am humidity & - & 1 & $-0.31^{*}$ & $0.63^{*}$ & 0.11 & $0.24^{*}$ \\
3:00 pm temperature & - & - & 1 & $-0.57^{*}$ & $0.59^{*}$ & $0.42^{*}$ \\
3:00 pm humidity & - & - & - & $-0.47^{*}$ & $-0.41^{*}$ \\
Temperature difference & - & - & - & - & - & $0.69^{*}$ \\
Humidity difference & - & - & - & - & 1 \\
\hline
\end{tabular}

*Significant bivariate correlation, $P$ value $<0.05$ 
Table 3 Univariable analysis of the association between weather factors and reported cases of COVID-19 caused by the B.1.617.2 (delta) variant of SARS-CoV-2, Sydney, Australia from 16 June to 10 September, 2021

\begin{tabular}{lccc}
\hline Factor & Estimate $(\mathbf{9 5 \%} \mathbf{C l})$ & Likelihood ratio & $\boldsymbol{P}$-value \\
\hline 9:00 am humidity & $-0.15(-0.18,-0.12)$ & -10.49 & $<0.001$ \\
9:00 am tempera- & $0.68(0.52,0.85)$ & 8.00 & $<0.001$ \\
ture & & & \\
Humidity difference & $-0.03(-0.15,0.09)$ & -0.49 & 0.621 \\
\hline l & & &
\end{tabular}

of humidity on transmission of the delta variant might be greater than that for the original SARS-CoV-2. The SARS$\mathrm{CoV}-2$ delta variant emerged recently and it has spread globally. Reports suggest that it might be more than twice as transmissible as the original SARS-CoV-2 that emerged in 2019-2020 [22]. To our knowledge there are no published studies specifically focusing on the relationship between transmission of the delta variant and weather. Further studies are needed to confirm the stronger association found in this study between transmission of the delta variant and humidity, and whether increased transmissibility might be partly explained by weather factors. This might provide useful information for policymakers to control transmission of the delta variant, for example by increasing indoors relative humidity to more than $70 \%$ in high-risk environments during times of the year in which transmission of this variant is favored.

Table 4 Multivariable analysis of weather factors (14-day exponential moving average) and reported cases of COVID-19 caused by the B.1.617.2 (delta) variant of SARS-CoV-2, Sydney, Australia from 16 June to 10 September, 2021

\begin{tabular}{|c|c|c|c|c|}
\hline Model & Factor & Estimate $(95 \% C l)$ & Likelihood ratio & $P$-value \\
\hline \multirow[t]{2}{*}{1} & Intercept & $16.37(14.31,18.44)$ & 15.52 & $<0.001$ \\
\hline & 9:00 am humidity & $-0.15(-0.18,-0.12)$ & -10.49 & $<0.001$ \\
\hline \multirow[t]{2}{*}{2} & Intercept & $-2.74(-4.76,-0.73)$ & -2.66 & 0.008 \\
\hline & 9:00 am temperature & $0.68(0.52,0.85)$ & 8.00 & $<0.001$ \\
\hline \multirow[t]{3}{*}{3} & Intercept & $10.24(5.03,15.45)$ & 3.86 & $<0.001$ \\
\hline & 9:00 am humidity & $-0.11(-0.15,-0.07)$ & -5.30 & $<0.001$ \\
\hline & 9:00 am temperature & $0.25(0.03,0.47)$ & 2.21 & 0.027 \\
\hline \multirow[t]{4}{*}{4} & Intercept & $-34.29(-51.80,-16.78)$ & -3.84 & $<0.001$ \\
\hline & 9:00 am humidity & $0.52(0.27,0.76)$ & 4.20 & $<0.001$ \\
\hline & 9:00 am temperature & $4.23(2.76,5.70)$ & 5.65 & $<0.001$ \\
\hline & $\begin{array}{l}\text { 9:00 am humidity } \times \text { 9:00 am tem- } \\
\text { perature }\end{array}$ & $-0.06(-0.08,-0.04)$ & -5.34 & $<0.001$ \\
\hline
\end{tabular}

Cl confidence interval

Table 5 Comparison of three multivariable models of the association between weather factors (14-day exponential moving average) and reported cases of COVID-19 caused by the B.1.617.2 (delta) variant of SARS-CoV-2, Sydney, Australia from 16 June to 10 September, 2021

\begin{tabular}{|c|c|c|c|c|c|}
\hline Model & Parameter & AIC & Comparison & Likelihood ratio & $P$-value \\
\hline \multirow[t]{2}{*}{1} & Intercept & $1,137.50$ & - & - & - \\
\hline & 9:00 am humidity & & & & \\
\hline \multirow[t]{2}{*}{2} & Intercept & $1,151.62$ & Model 2 vs Model 3 & 18.53 & $<0.001$ \\
\hline & 9:00 am temperature & & & & \\
\hline \multirow[t]{3}{*}{3} & Intercept & $1,135.09$ & Model 1 vs Model 3 & 4.40 & 0.036 \\
\hline & 9:00 am humidity & & & & \\
\hline & 9:00 am temperature & & & & \\
\hline \multirow[t]{4}{*}{4} & Intercept & $1,119.64$ & Model 3 vs Model 4 & 17.46 & $<0.001$ \\
\hline & 9:00 am humidity & & & & \\
\hline & 9:00 am temperature & & & & \\
\hline & $\begin{array}{l}\text { 9:00 am humidity } \times \text { 9:00 am } \\
\text { temperature }\end{array}$ & & & & \\
\hline
\end{tabular}



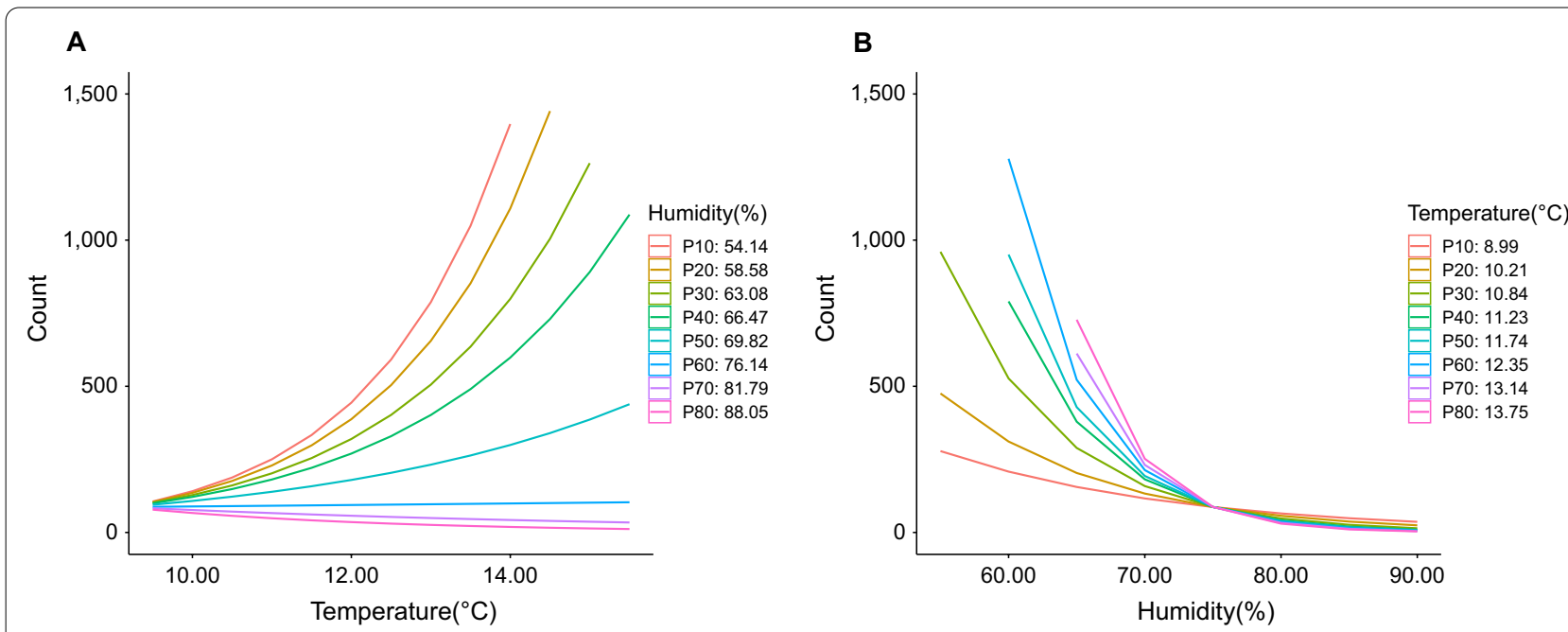

Fig. 3 Interaction plots between 9:00 am temperature and 9:00 am relative humidity in a model of reported cases (counts) of COVID-19 caused by the B.1.617.2 (delta) variant of SARS-CoV-2, Sydney, Australia from 16 June to 10 September 2021. Interactions are shown using deciles of humidity (left, A) and temperature (right, B). The different lines represent the percentiles indicated

Table 6 Sensitivity analysis for the comparison of three multivariable models of the association between weather factors (14-day exponential moving average) and reported cases of COVID-19 caused by the B.1.617.2 (delta) variant of SARS-CoV-2, Sydney, Australia from 16 June to 10 September, 2021

\begin{tabular}{|c|c|c|c|c|c|c|c|c|c|c|}
\hline \multirow[t]{3}{*}{ Model } & \multirow[t]{3}{*}{ Factor } & \multicolumn{9}{|c|}{ Days used for exponential moving average } \\
\hline & & \multicolumn{3}{|l|}{ 7-day } & \multicolumn{3}{|l|}{ 14-day } & \multicolumn{3}{|l|}{ 21-day } \\
\hline & & Estimate (SE) & Z & $P$-value & Estimate (SE) & Z & $P$-value & Estimate (SE) & Z & $P$-value \\
\hline \multirow[t]{2}{*}{1} & Intercept & $14.59(1.13)$ & 12.89 & $<0.001$ & $16.37(1.06)$ & 15.52 & $<0.001$ & $17.30(0.82)$ & 21.16 & $<0.001$ \\
\hline & 9:00 am humidity & $-0.13(0.02)$ & -8.23 & $<0.001$ & $-0.15(0.01)$ & -10.49 & $<0.001$ & $-0.16(0.01)$ & -14.55 & $<0.001$ \\
\hline \multirow[t]{2}{*}{2} & Intercept & $-1.03(0.05)$ & -22.3 & $<0.001$ & $-2.74(1.03)$ & -2.66 & 0.008 & $-3.64(0.86)$ & -4.23 & $<0.001$ \\
\hline & 9:00 am temperature & $0.54(0.003)$ & 158.0 & $<0.001$ & $0.68(0.09)$ & 8.00 & $<0.001$ & $0.77(0.07)$ & 10.70 & $<0.001$ \\
\hline \multirow[t]{3}{*}{3} & Intercept & $3.89(0.12)$ & 33.18 & $<0.001$ & $10.24(2.66)$ & 3.86 & $<0.001$ & $11.28(2.29)$ & 4.93 & $<0.001$ \\
\hline & 9:00 am humidity & $-0.05(0.001)$ & -44.97 & $<0.001$ & $-0.11(0.02)$ & -5.30 & $<0.001$ & $-0.12(0.02)$ & -7.00 & $<0.001$ \\
\hline & 9:00 am temperature & $0.40(0.005)$ & 86.44 & $<0.001$ & $0.25(0.11)$ & 2.21 & 0.027 & $0.25(0.10)$ & 2.55 & 0.011 \\
\hline \multirow[t]{4}{*}{4} & Intercept & $-8.33(8.05)$ & -1.03 & 0.301 & $-34.29(8.93)$ & -3.84 & $<0.001$ & $-42.85(7.65)$ & -5.60 & $<0.001$ \\
\hline & 9:00 am humidity & $0.13(0.11)$ & 1.22 & 0.224 & $0.52(0.12)$ & 4.20 & $<0.001$ & $0.66(0.11)$ & 6.10 & $<0.001$ \\
\hline & 9:00 am temperature & $1.67(0.66)$ & 2.55 & 0.011 & $4.23(0.75)$ & 5.65 & $<0.001$ & $5.17(0.66)$ & 7.83 & $<0.001$ \\
\hline & $\begin{array}{l}\text { 9:00 am humid- } \\
\text { ity } \times \text { 9:00 am tem- } \\
\text { perature }\end{array}$ & $-0.02(0.01)$ & -2.05 & 0.040 & $-0.06(0.01)$ & -5.34 & $<0.001$ & $-0.07(0.01)$ & -7.48 & $<0.001$ \\
\hline
\end{tabular}

The effect of humidity on transmission of SARS$\mathrm{CoV}-2$ virus has received substantial attention during 2020 and 2021, including studies conducted in Bangladesh [10] and China [4, 23, 24], and systematic reviews on the topic [25]. However, no consistent conclusion has been made. In several studies from 166 countries [24], China and the US [26] and Bangladesh [10], high relative humidity was found to be associated with a reduction in the daily number of COVID-19 cases or the effective reproductive number of SARS-CoV-2.
In 30 Chinese provincial capitals, Liu et al. [23] found that low humidity likely favors SARS-CoV-2 transmission. In addition, using quantitative time-series analysis techniques, Qi et al. [4] estimated that for every $1 \%$ increase in relative humidity, daily confirmed cases decreased by $11 \%$ to $22 \%$ when temperature was in the range of $5.04-8.2^{\circ} \mathrm{C}$. In the current study, we also found that humidity was negatively related to daily COVID-19 cases and was a stable driver of SARS-CoV-2 transmission, consistent with the above studies. However, the 
observed relationship between COVID-19 cases and humidity has not always been consistent; for example, this relationship was found to be heterogeneous between different cities in China [12], and in a global study of 190 countries an inverse J-shaped relationship was found between relative humidity and COVID-19 incidence, in which risk was greatest at $72 \%$ relative humidity [7]. It is likely that a range of other factors influences the relationship between transmission of SARS-CoV-2 and humidity, particularly climatic zone. Also, the various control strategies implemented-such as mandatory mask-wearing, social distancing, testing and vaccination-make characterization of the relationship between weather factors and SARS-CoV-2 transmission within outbreak situations challenging.

The relationship between temperature and COVID19 cases has not yet been fully characterized. In a study in China, no relationship between temperature and COVID-19 cases was found [27]. A negative correlation between temperature and COVID-19 cases-less transmission at higher temperatures-has been reported by Xie et al. [28] and Notari et al. [29]. However, in our study, a positive correlation between temperature and COVID-19 cases caused by the SARS-CoV-2 delta variant was found, but only in the situation when relative humidity values are around $70 \%$ or lower. This is consistent with positive associations between average temperature and daily COVID-19 cases reported in nine Asian cities [30].

The interactions among weather factors might provide a reasonable explanation for the above contradictory results. Previous research has suggested a potential interaction between relative humidity and temperature and COVID-19 case reports, but the exact mechanism of the interaction is unclear [4]. This might be due to both temperature and humidity affecting the function of the respiratory mucosa as a barrier to the virus and infection, and hence affecting the spread of SARS-CoV-2 [31]. The same phenomenon has been previously described in influenza studies: temperature was inversely associated with influenza and the relationship could be modified by humidity [32]. Hence the suggestion has been made that COVID-19 might develop into a seasonal disease [33]. However, studies on the correlation between weather factors such as temperature and humidity and their interaction and transmission of the SARS-CoV-2 delta variant have not yet been reported, and further research is urgently needed to support policy and control. Our results suggest that weather could be a more important consideration during outbreaks of this delta variant. Therefore, it is important in future research to focus on those specific periods in which transmission might be increased to better understand the mechanisms involved and how public health advice and interventions might be targeted. Given the advances that have been made in forecasting seasonal influenza outbreaks [34], the same approach can be anticipated for seasonal COVID-19 once the mechanisms of spread are better understood.

In this study we assumed that cases were infected within their LHD and that temperature and humidity measured at meteorological recording stations was a proxy for the conditions experienced when transmission occurred. More precise measures of exposure are difficult to access in the field and within an outbreak setting. Temperature and humidity measurements represent outdoors conditions, and so are a proxy for the conditions experienced by the population exposed to infection. We also assumed that case reporting in this outbreak was high and that differential bias was not present. During this outbreak high levels of testing occurred-an average daily testing rate of $>80,000$ tests were reported-and confirmation rates remained consistent [16], so reporting bias is likely small. Although observational studies such as the current one suffer from measurement and information biases, the coherence of evidence from a growing number of studies strengthens the hypothesis that SARS$\mathrm{CoV}-2$ transmission is influenced by weather.

\section{Conclusions}

To date, countries in the northern hemisphere have not experienced large outbreaks of COVID-19 caused by the delta variant of SARS-CoV-2 during the winter months. The present study contributes to our growing knowledge of the relationship between SARS-CoV-2 transmission and weather, and specifically the transmission of the delta variant, which is currently the dominant variant globally. It suggests that both relative humidity and temperature play a role via an interactive effect. In similar climatic zones to this study in which low humidity and mild temperatures are experienced during the winter months, the control of the delta variant might be more difficult than previously expected. Increasing the ambient humidity (e.g., > 70\%) might be a useful alternative measurement for reducing the transmission risk of the delta variant of SARS-CoV-2 in the future, and during periods of anticipated increased risk (such as the winter months) additional disease control interventions might be warranted.

\section{Abbreviations}

AIC: Akaike information criterion; EMA: Exponential moving average; GAM: Generalized additive model; LHD: Local health district; $\rho$ : Spearman rank correlation. 


\section{Supplementary Information}

The online version contains supplementary material available at https://doi. org/10.1186/s40249-021-00926-0.

Additional file 1. Data used to analyse the association between weather variables and reported cases of COVID-19 caused by the B.1.617.2 (delta) variant of SARS-CoV-2 in Sydney, Australia between June and September 2021.

\section{Acknowledgements}

NSW Ministry of Health is thanked for freely making available COVID-19 case notification data.

\section{Authors' contributions}

MPW conceptualized the study, curated the data, designed the methodology, interpreted analysis and drafted, reviewed and edited the paper. YL undertook data analysis and drafted the paper. SX undertook data visualization and analysis. ZZ conceptualized the study, designed the methodology, interpreted analysis and drafted, reviewed and edited the paper. All authors read and approved the final manuscript.

\section{Funding}

ZZ is supported by the Major Project of Scientific and Technical Winter Olympics from National Key Research and Development Program of China (2021YFF0306000), Public Health Talents Training Program of Shanghai Municipality (GWV-10.2-XD21), and the National Natural Science Foundation of China (81973102).

\section{Availability of data and materials}

All data analysed during this study are included in this published article (and its Additional files).

\section{Declarations}

Ethics approval and consent to participate

Not applicable.

\section{Consent for publication}

Not applicable.

\section{Competing interests}

The authors declare that they have no competing interests.

\section{Author details}

${ }^{1}$ Sydney School of Veterinary Science, The University of Sydney, Camden, NSW, Australia. ${ }^{2}$ School of Public Health, Fudan University, Shanghai, China. ${ }^{3}$ Department of HIV/STD Prevention and Control, Shanghai Municipal Centre for Disease Control and Prevention, Shanghai, China.

\section{Received: 21 October 2021 Accepted: 15 December 2021}

\section{Published online: 23 December 2021}

\section{References}

1. Cai J, Sun W, Huang J, Gamber M, Wu J, He G. Indirect virus transmission in cluster of COVID-19 cases, Wenzhou, China, 2020. Emerg Infect Dis. 2020;26:1343-5. https://doi.org/10.3201/eid2606.200412.

2. Yeo C, Kaushal S, Yeo D. Enteric involvement of coronaviruses: is faecaloral transmission of SARS-CoV-2 possible? Lancet Gastroenterol Hepatol. 2020:5:335-7. https://doi.org/10.1016/S2468-1253(20)30048-0.

3. SanJuan-Reyes S, Gomez-Olivan LM, Islas-Flores H. COVID-19 in the environment. Chemosphere. 2021;263: 127973. https://doi.org/10.1016/j. chemosphere.2020.127973.

4. Qi H, Xiao S, Shi R, Ward MP, Chen Y, Tu W, et al. COVID-19 transmission in mainland China is associated with temperature and humidity: a timeseries analysis. Sci Total Environ. 2020;728: 138778. https://doi.org/10. 1016/j.scitotenv.2020.138778.
5. Guo XJ, Zhang H, Zeng YP. Transmissibility of COVID-19 in 11 major cities in China and its association with temperature and humidity in Beijing, Shanghai, Guangzhou, and Chengdu. Infect Dis Poverty. 2020;9:87. https://doi.org/10.1186/s40249-020-00708-0.

6. Tosepu R, Gunawan J, Effendy DS, Ahmad O, Lestari H, Bahar H, Asfian P. Correlation between weather and COVID-19 pandemic in Jakarta, Indonesia. Sci Total Environ. 2020;725: 138436. https://doi.org/10.1016/j.scito tenv.2020.138436.

7. Guo C, Bo Y, Lin C, Li HB, Zeng Y, Zhang Y, et al. Meteorological factors and COVID-19 incidence in 190 countries: an observational study. Sci Total Environ. 2021;757: 143783. https://doi.org/10.1016/j.scitotenv. 2020.143783.

8. Ward MP, Xiao S, Zhang Z. The role of climate during the COVID-19 epidemic in New South Wales, Australia. Transbound Emerging Dis. 2020;67:2313-7. https://doi.org/10.1111/tbed.13631.

9. Ward MP, Xiao S, Zhang Z. Humidity is a consistent climatic factor contributing to SARS-CoV-2 transmission. Transbound Emerging Dis. 2020;67:3069-2074. https://doi.org/10.1111/tbed.13766.

10. Haque SE, Rahman M. Association between temperature, humidity, and COVID-19 outbreaks in Bangladesh. Environ Sci Policy. 2020;114:253-5. https://doi.org/10.1016/j.envsci.2020.08.012.

11. Runkle JD, Sugg MM, Leeper RD, Rao Y, Matthews JL, Rennie JJ. Shortterm effects of specific humidity and temperature on COVID-19 morbidity in select US cities. Sci Total Environ. 2020;740: 140093. https:// doi.org/10.1016/j.scitotenv.2020.140093.

12. Xiao S, Qi H, Ward MP, Wang W, Zhang J, Chen Y, et al. Meteorological conditions are heterogeneous factors for COVID-19 risk in China. Environ Res. 2020;198: 111182. https://doi.org/10.1016/j.envres.2021. 111182.

13. World Health Organization. Weekly epidemiological update on COVID-19 - 24 August 2021. https://www.who.int/publications/m/ item/weekly-epidemiological-update-on-covid-19---24-august-2021. Accessed 2 September 2021.

14. NSW Government. Public health alert - COVID-19 case, 16 June 2021. https://www.health.nsw.gov.au/news/pages/20210616 01.aspx. Accessed 2 September 2021.

15. NSW Government. Data. NSW: COVID-19 cases by notification date, location. https://data.nsw.gov.au/dataset/nsw-covid-19-tests-by-locat ion-and-result. Accessed 3 October 2021

16. NSW Government, Health. COVID-19 Weekly Surveillance in NSW. http://www.health.nsw.gov.au/coronavirus. Accessed 18 November 2021

17. Australian Government. New South Wales weather observation stations. http://www.bom.gov.au/nsw/observations/map.shtml. Accessed 3 October 2021.

18. NSW Government, Health. COVID-19 (Coronavirus) statistics. https:// www.health.nsw.gov.au/news/pages/default.aspx. Accessed 3 October 2021.

19. Citymapper Mobility Index. https://citymapper.com/cmi/sydney. Accessed 7 September 2021.

20. Heibati B, Wang WG, Ryti NRI, Dominici F, Ducatman A, Zhang ZJ, Jaakkola JJK. Weather conditions and COVID-19 incidence in a cold climate: a time-series study in Finland. Front Public Health. 2021;8: 605128. https:// doi.org/10.3389/fpubh.2020.605128.

21. R 4.0.1 software. R Foundation for Statistical Computing, Vienna, Austria. https://cran.wu.ac.at/. Accessed 3 October 2021.

22. Allen H, Vusirikala A, Flannagan J, Twohig KA, Zaidi A, Chudasama D, et al. Household transmission of COVID-19 cases associated with SARS-CoV-2 delta variant (B.1.617.2): national case-control study. Lancet Reg Health Eur. 2021:100252.

23. Liu J, Zhou J, Yao J, Zhang X, Li L, Xu X, et al. Impact of meteorological factors on the COVID-19 transmission: a multi-city study in China. Sci Total Environ. 2020;726: 138513. https://doi.org/10.1016/j.scitotenv.2020. 138513.

24. Wu Y, Jing W, Liu J, Ma Q, Yuan J, Wang Y, et al. Effects of temperature and humidity on the daily new cases and new deaths of COVID-19 in 166 countries. Sci Total Environ. 2020;729: 139051. https://doi.org/10.1016/j. scitotenv.2020.139051.

25. Guo L, Yang Z, Zhang L, Wang S, Bai T, Xiang Y, Long E. Systematic review of the effects of environmental factors on virus inactivation: implications 
for coronavirus disease 2019. Int J Environ Sci Technol. 2021;18:2865-78. https://doi.org/10.1007/s13762-021-03495-9.

26. Wang J, Tang K, Feng K, Lv W. High temperature and high humidity reduce the transmission of COVID-19. BMJ Open. 2020;11: e043863. https://doi.org/10.2139/ssrn.3551767.

27. Wang Q, Zhao Y, Zhang Y, Qiu J, Li J, Yan N, et al. Could the ambient higher temperature decrease the transmissibility of COVID-19 in China? Environ Res. 2021;193: 110576. https://doi.org/10.1016/j.envres.2020.110576.

28. Xie J, Zhu Y. Association between ambient temperature and COVID-19 infection in 122 cities from China. Sci Total Environ. 2020;724: 138201. https://doi.org/10.1016/j.scitotenv.2020.138201.

29. Notari A. Temperature dependence of COVID-19 transmission. Sci Total Environ. 2020;763: 144390. https://doi.org/10.1016/j.scitotenv.2020. 144390.

30. He Z, Chin Y, Yu S, Huang J, Zhang C, Zhu K, et al. The influence of average temperature and relative humidity on new cases of COVID-19: time-series analysis. JMIR Public Health Surveill. 2021;7: e20495. https://doi.org/10. 2196/20495.

31. Moriyama M, Hugentobler WJ, Iwasaki A. Seasonality of respiratory viral infections. Annu Rev Virol. 2020;7:83-101. https://doi.org/10.1146/annur ev-virology-012420-022445.

32. Liu Z, Zhang J, Zhang Y, Lao J, Liu Y, Wang H, Jiang B. Effects and interaction of meteorological factors on influenza: based on the surveillance data in Shaoyang, China. Environ Res. 2019;172:326-32. https://doi.org/ 10.1016/j.envres.2019.01.053.

33. Audi A, Allbrahim M, Kaddoura M, Hijazi G, Yassine HM, Zaraket H. Seasonality of respiratory viral infections: will COVID-19 follow suit? Front Public Health. 2020;8: 567184. https://doi.org/10.3389/fpubh.2020.567184.

34. Shaman J, Karspeck A. Forecasting seasonal outbreaks of influenza. PNAS. 2012;109:20425-30. https://doi.org/10.1073/pnas.1208772109.

Ready to submit your research? Choose BMC and benefit from:

- fast, convenient online submission

- thorough peer review by experienced researchers in your field

- rapid publication on acceptance

- support for research data, including large and complex data types

- gold Open Access which fosters wider collaboration and increased citations

- maximum visibility for your research: over $100 \mathrm{M}$ website views per year

At BMC, research is always in progress.

Learn more biomedcentral.com/submissions 